\title{
Review:
}

\section{Challenges faced in the clinical application of artificial anal sphincters"}

\author{
Ming-hui $\mathrm{WANG}^{1}$, Ying ZHOU ${ }^{1}$, Shuang ZHAO ${ }^{1,2}$, Yun LUO ${ }^{\$ 1}$ \\ ( ${ }^{I}$ State Key Laboratory of Mechanical System and Vibration, Institute of Biomedical Manufacturing and Life Quality Engineering, \\ School of Mechanical Engineering, Shanghai Jiao Tong University, Shanghai 200240, China) \\ $\left({ }^{2}\right.$ School of Mechanical Engineering, Shanghai Dianji University, Shanghai 200240, China) \\ ${ }^{\dagger} E-m a i l: 1$ luoyun@sjtu.edu.cn \\ Received Sept. 10, 2014; Revision accepted Aug. 4, 2015; Crosschecked Aug. 17, 2015
}

\begin{abstract}
Fecal incontinence is an unresolved problem, which has a serious effect on patients, both physically and psychologically. For patients with severe symptoms, treatment with an artificial anal sphincter could be a potential option to restore continence. Currently, the Acticon Neosphincter is the only device certified by the US Food and Drug Administration. In this paper, the clinical safety and efficacy of the Acticon Neosphincter are evaluated and discussed. Furthermore, some other key studies on artificial anal sphincters are presented and summarized. In particular, this paper highlights that the crucial problem in this technology is to maintain long-term biomechanical compatibility between implants and surrounding tissues. Compatibility is affected by changes in both the morphology and mechanical properties of the tissues surrounding the implants. A new approach for enhancing the long-term biomechanical compatibility of implantable artificial sphincters is proposed based on the use of smart materials.
\end{abstract}

Key words: Fecal incontinence (FI), Artificial anal sphincter (AAS), Biomechanical compatibility, Smart materials doi:10.1631/jzus.B1400242 Document code: A CLC number: R322.4 $4^{+} 6$

\section{Introduction}

Fecal incontinence (FI) caused by sphincter dysfunction is a difficult medical problem, which has not been fully resolved. It can cause enormous psychological trauma and extreme discomfort for patients, and has afflicted humans for thousands of years. FI is the inability to control the passage of feces through the anus (Madoff et al., 2004; Rao, 2004; Rojas et al., 2014), and morbidity increases with advancing age. It is estimated that about $1.4 \%$ of adults

\footnotetext{
Corresponding author

* Project supported by the Shanghai Pujiang Program (No. 09PJ1406500), the National Natural Science Foundation of China (Nos. 30970704, 51075263, 51121063, and 50821003), and the Foundation from the State Key Laboratory of Mechanical Systems and Vibration (No. MSVZD201203), China

(1) ORCID: Ming-hui WANG, http://orcid.org/0000-0002-2957-3211

(C) Zhejiang University and Springer-Verlag Berlin Heidelberg 2015
}

(Perry et al., 2002; Walter et al., 2002), 6\%-7\% of elderly people, and $10 \%$ of patients in elderly nursing homes suffer from FI (Tobin and Brocklehurst, 1986; Madoff et al., 2004; Teunissen et al., 2006; Tan et al., 2007). However, it is difficult to establish its true prevalence (Madoff et al., 2004; Rojas et al., 2014).

From a medical perspective, treatment methods for FI include nonsurgical and surgical treatments. Most patients prefer nonsurgical treatment, such as drug therapy or biofeedback, and surgical treatments, such as sacral nerve stimulation, sphincteroplasty, postanal repair, dynamic graciloplasty, or colostomy, are chosen only when nonsurgical treatments are ineffectual (Baig and Wexner, 2000; Tan et al., 2007). Surgical repairs usually achieve only a remission of symptoms. Therefore, the medical methods are not effective enough to manage the symptoms of FI (Kaiser et al., 2014; Mitchell and Sagar, 2014; Nandivada and Nagle, 2014). 
From an engineering perspective, an artificial device replacing the sphincter is a potential treatment method. The history of research on artificial sphincters dates back more than half a century. Initially, artificial urinary sphincters were studied, and the clinical application of such sphincters achieved by American Medical Systems (AMS) inspired some researchers to use similar devices for treating anal incontinence. The study by Christiansen and Lorentzen (1987) was the first to attempt using an AMS800 artificial urinary sphincter to treat FI, and subsequently this device was modified to meet the demands of a bowel sphincter (strengthened cuff-tab, wider cuffs, and an enlarged pressure regulating balloon). Eventually, a specific artificial anal sphincter (AAS), the Acticon Neosphincter (AMS, Minnetonka, MN, USA), was designed. In 1999, the device received a humanitarian device exemption of US Food and Drug Administration (FDA) and was formally FDAapproved in 2001 (Gregorcyk, 2005). The device has been implanted in many patients.

The Acticon Neosphincter consists of three components integrated by kink-resistant tubing: an inflatable cuff placed around the anus, a manual control pump placed under the skin of the scrotum in males or labia in females, and a pressure-regulating balloon implanted extraperitoneally (Fig. 1). The purpose of the device is to take over from the muscle to control the opening and closing of the anus (AMS, 1999).

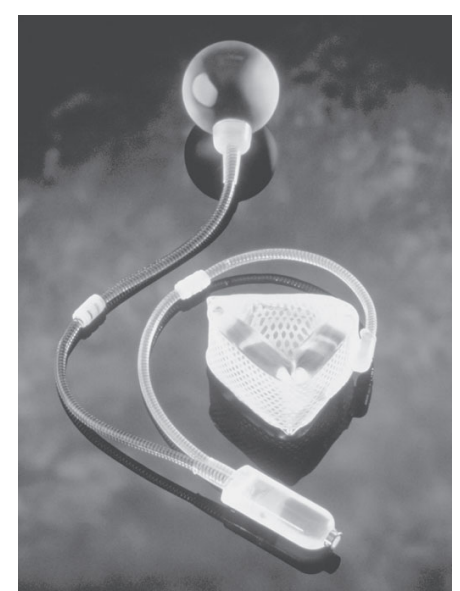

Fig. 1 Acticon Neosphincter

American Medical Systems, Inc., Minnetonka, MN, USA (https://pelvichealthsource.com/content/dam/wph/us-region/ en/documents/labeling/fecal-incontinence/1006168.r03 ORMan_Acticon_en.pdf)
When a patient wishes to defecate, the bulb on the control pump is manually squeezed and released several times. This transfers the fluid from the cuff to the balloon through the tube, thereby deflating the cuff and allowing the stool to pass. Pressure from the balloon slowly forces the fluid back into the cuff over several minutes, and consequently closes the anus (AMS, 1999).

In this paper, the outcomes of the clinical application of the AMS series sphincter, in terms of both safety and efficacy, will be summarized. Some of the main researches on devices intended to achieve the continence of feces will also be discussed. Maintaining long-term biomechanical compatibility between the artificial sphincter and the surrounding tissue is the key problem of AAS in clinical application. A novel concept involving embedding smart material in the device to improve its biomechanical compatibility will be presented.

\section{Results of the clinical application of the AMS series sphincter}

The clinical application of AAS has been studied by many experts, and this paper summarizes and analyzes the most important 24 studies from 1996 to 2010 (Lehur et al., 1996; 1998; 2000; 2002; Wong et al., 1996; 2002; Vaizey et al., 1998; Christiansen et al., 1999; Dodi et al., 2000; Malouf et al., 2000; O'Brien and Skinner, 2000; Altomare et al., 2001; 2004; Devesa et al., 2002; Ortiz et al., 2002; Michot et al., 2003; Parker et al., 2003; Romano et al., 2003; Casal et al., 2004; O'Brien et al., 2004; Ruiz Carmona et al., 2009; Gallas et al., 2009; Meurette et al., 2009; Chittawatanarat et al., 2010). These studies focused chiefly on results from the clinical application of the AMS series sphincter (the unmodified AMS800, the modified version of the AMS800, and the final version, the Acticon Neosphincter) from the point of view of safety and efficacy. The longest follow-up period was 10 years after implantation (Christiansen et al., 1999) and the shortest was only 6 months (O'Brien et al., 2004). The largest case included 115 patients (Wong et al., 2002) and the smallest only 6 (Chittawatanarat et al., 2010). Five of the studies are considered to be of high quality, among which four were carried out by Lehur et al. $(1996 ; 1998 ; 2000$; 2002), in whose research the selected patients were 
continuous, and one by Wong et al. (2002), which is the largest study with 115 patients.

\subsection{Safety}

\subsubsection{Explantation}

Twenty-two papers (Lehur et al., 1996; 1998; 2000; 2002; Wong et al., 1996; 2002; Vaizey et al., 1998; Christiansen et al., 1999; Dodi et al., 2000; Malouf et al., 2000; O'Brien and Skinner, 2000; Altomare et al., 2001; 2004; Devesa et al., 2002; Ortiz et al., 2002; Michot et al., 2003; Parker et al., 2003; Casal et al., 2004; O'Brien et al., 2004; Ruiz Carmona et al., 2009; Gallas et al., 2009; Chittawatanarat et al., 2010) reported data about the explantation rate of the device, which varied between $14 \%$ and $65 \%$ (Ruiz Carmona et al., 2009). In four papers of Lehur et al. $(1996 ; 1998 ; 2000 ; 2002)$, the explantation rates were $23 \%, 31 \%, 29 \%$, and $31 \%$, respectively. In the paper of Wong et al. (2002), the rate was $37 \%$. The reason that explants were required varied among patients. The most common reason was infection, followed by erosion, as well as the coexistence of infection and erosion. Mechanical complications were also common. Other reasons included pain, faulty devices, and dissatisfaction of the patients (Mundy et al., 2004).

\subsubsection{Surgical revision}

Fifteen papers (Lehur et al., 1998; 2000; 2002; Christiansen et al., 1999; Malouf et al., 2000; O'Brien and Skinner, 2000; Altomare et al., 2001; 2004; Devesa et al., 2002; Wong et al., 2002; Parker et al., 2003; O'Brien et al., 2004; Ruiz Carmona et al., 2009; Gallas et al., 2009; Meurette et al., 2009) reported data about surgical revision, which varied between 13\% (Lehur et al., 2002) and 65\% (Ruiz Carmona et al., 2009). In three papers of Lehur et al. (1998; $2000 ; 2002$ ), the frequencies of surgical revision were $46 \%, 38 \%$, and $13 \%$, respectively. In the paper of Wong et al. (2002), 51 of 97 patients underwent 73 revision surgeries. Infection, erosion, and mechanical malfunction were the main reasons for surgical revision. Other causes included fecal impaction, pain, and rupture of the perineal wound (Mundy et al., 2004).

\subsubsection{Infection}

Seventeen papers (Lehur et al., 1996; 1998; 2000; Wong et al., 1996; 2002; Vaizey et al., 1998;
Christiansen et al., 1999; Dodi et al., 2000; Malouf et al., 2000; O'Brien and Skinner, 2000; Altomare et al., 2001; Devesa et al., 2002; Ortiz et al., 2002; Parker et al., 2003; Casal et al., 2004; Ruiz Carmona et al., 2009; Chittawatanarat et al., 2010) reported the infection rate, which varied between $4 \%$ (Lehur et al., 2000 ) and 50\% (Chittawatanarat et al., 2010). In three papers of Lehur et al. (1996; 1998; 2000), the frequencies of infection were $15 \%, 8 \%$, and $4 \%$, respectively. In the paper of Wong et al. (2002), 38 of 112 patients were infected, and 28 of the 38 patients needed surgical revision.

The location of early infection produced before activation of the device involved mainly the perineum or abdomen. Post-activation infections were caused mainly by the erosion of the device. As the location of the artificial sphincter implant is in the anorectal region, the risk of infection is much larger than that of other operations (Christiansen, 2000; Mundy et al., 2004).

\subsubsection{Erosion}

Sixteen papers (Lehur et al., 1996; 1998; 2000; 2002; Vaizey et al., 1998; Dodi et al., 2000; Malouf et al., 2000; O'Brien and Skinner, 2000; Altomare et al., 2001; Devesa et al., 2002; Ortiz et al., 2002; Wong et al., 2002; Michot et al., 2003; Casal et al., 2004; Ruiz Carmona et al., 2009; Chittawatanarat et al., 2010) reported the frequency of erosion, which varied between 6\% (Lehur et al., 2002) and 33\% (Chittawatanarat et al., 2010). In four papers of Lehur et al. $(1996 ; 1998 ; 2000 ; 2002)$, the frequencies were $8 \%$, $8 \%, 17 \%$, and $6 \%$, respectively. In the paper of Wong et al. (2002), the frequency was $21 \%$. Erosion of the anal canal was most frequent, followed by cuff erosion, pump erosion, pipe erosion, rectum erosion, and erosion of other components. The causes of erosion might be infection, organizational pressure, repeated straining during defecation, inappropriate cuff size, the choice of balloon, or tissue damage.

\subsubsection{Mechanical complications}

Nine papers (Lehur et al., 1996; Wong et al., 1996; Christiansen et al., 1999; Devesa et al., 2002; Ortiz et al., 2002; Michot et al., 2003; Altomare et al., 2004; Casal et al., 2004; Ruiz Carmona et al., 2009) mentioned mechanical complications, the frequency of which varied between $2 \%$ (Devesa et al., 2002) and 
29\% (Ruiz Carmona et al., 2009). The mechanical failure rate reported by Lehur et al. (1996) was $23 \%$. These complications included rupture of the cuff, loss of fluid from the system, disconnection of any component, and malfunction or migration of the control pump. The main causes were the complexity of the device and the connectivity of its components.

\subsubsection{Other complications}

Evacuation difficulties were experienced by $83 \%$ of patients (Vaizey et al., 1998). The frequencies of evacuation difficulties reported in three papers of Lehur et al. $(1996 ; 2000 ; 2002)$ were $31 \%, 38 \%$, and $31 \%$, respectively. However, causes of this problem are still unclear. A short cuff and a short opening time of the device are correlated with poor emptying of the rectum (Savoye et al., 2000; Michot et al., 2003).

Other frequent complications included tissue ischemia, fecal obstruction, constipation, pain, rectal prolapse, fever, and hematoma.

\subsection{Efficacy}

\subsubsection{Fecal incontinence score}

Fifteen papers (Wong et al., 1996; 2002; Lehur et al., 1998; 2000; 2002; Vaizey et al., 1998; Christiansen et al., 1999; Dodi et al., 2000; O'Brien and Skinner, 2000; Altomare et al., 2001; Parker et al., 2003; Romano et al., 2003; Casal et al., 2004; O'Brien et al., 2004; Chittawatanarat et al., 2010) used a fecal incontinence score (FIS) to assess the severity of incontinence of patients. Four scoring systems were adopted: Williams Scale (WS), AMS Fecal Incontinence Score (AMSFIS), Cleveland Continence Score (CCS), and Wexner Continence Grading Score (WCGS) (Jorge and Wexner, 1993; Vaizey et al., 1999; Mundy et al., 2004), as shown in Table 1.

Table 1 Fecal incontinence score (FIS)

\begin{tabular}{lccc}
\hline $\begin{array}{c}\text { FIS } \\
\text { system }\end{array}$ & $\begin{array}{c}\text { Normal } \\
\text { continence } \\
\text { score }\end{array}$ & $\begin{array}{c}\text { Complete } \\
\text { incontinence } \\
\text { score }\end{array}$ & $\begin{array}{c}\text { Number of } \\
\text { articles using } \\
\text { FIS }\end{array}$ \\
\hline WS & 0 & 5 & 1 \\
AMSFIS & 0 & 120 & 7 \\
CCS & 0 & 20 & 3 \\
WCGS & 0 & 20 & 4 \\
\hline
\end{tabular}

WS: Williams Scale; AMSFIS: AMS Fecal Incontinence Score; CCS: Cleveland Continence Score; WCGS: Wexner Continence Grading Score
Lehur et al. (2000; 2002) used AMSFIS. The mean score decreased significantly from 106 (standard deviation (SD), 13) and 105 (SD, 14) in the preoperative stage, to 25 (SD, 25) and $23(\mathrm{SD}, 22)$ at the end of the follow-up period, respectively. The difference between the preoperative and postoperative stages was statistically significant $(P<0.05)$. In another article using CCS (Lehur et al., 1998), the mean score decreased significantly from 17 (range, 14-20) in the preoperative stage to 4 (range, $0-10$ ) at the end of the study. In the study of Wong et al. (2002), the AMSFIS decreased from a median of 106 (range, 71-120) preoperatively to 48 (range, $0-120$ ) at 12 months after implantation. Statistical analysis revealed that the differences between the mean preimplantation FISs and those at 12-month follow-up were statistically significant $(P<0.0001)$. In all studies, the difference between the preoperative mean score and the postoperative mean score was quite large, i.e., FI had greatly improved, but the average score did not reflect the efficacy of the device.

\subsubsection{Quality of life}

Twelve studies (Wong et al., 1996; Vaizey et al., 1998; O'Brien and Skinner, 2000; Altomare et al., 2001; 2004; Lehur et al., 2002; Parker et al., 2003; Romano et al., 2003; O'Brien et al., 2004; Ruiz Carmona et al., 2009; Meurette et al., 2009; Chittawatanarat et al., 2010) assessed the quality of life (QL) and ten of those (Vaizey et al., 1998; O'Brien and Skinner, 2000; Altomare et al., 2001; 2004; Lehur et al., 2002; Parker et al., 2003; O'Brien et al., 2004; Ruiz Carmona et al., 2009; Meurette et al., 2009; Chittawatanarat et al., 2010) used one of the following scores: the AMS Quality of Life Scale (AMSQLS), Rockwood FI Quality of Life Score (RFIQLS), Short-Form 36 Questionnaire (SF-36), or the Beck Depression Inventory (BDI) (Wong et al., 1996; Lustman et al., 1997; Lehur et al., 2002; O'Brien et al., 2004; Meurette et al., 2009). The other two studies (Wong et al., 1996; Romano et al., 2003) assessed QL by questionnaire. All these FI quality of life scores showed a significant improvement from the preoperative to postoperative stages. In particular, Lehur et al. (2002) reported a significant improvement from a median of 0.44 (preoperative) to 0.84 (at the end of follow-up) with RFIQLS. The difference between the preoperative and postoperative values was statistically significant $(P<0.05)$. 


\subsubsection{Anal manometry}

Anorectal pressure is generally used to assess sphincter function, and the resting anal pressure reflects the function of the internal sphincter. Seventeen papers (Lehur et al., 1996; 1998; 2000; 2002; Wong et al., 1996; 2002; Vaizey et al., 1998; Dodi et al., 2000; Altomare et al., 2001; 2004; Devesa et al., 2002; Ortiz et al., 2002; Michot et al., 2003; Romano et al., 2003; Casal et al., 2004; Ruiz Carmona et al., 2009; Chittawatanarat et al., 2010) measured the anal pressure. The lowest mean resting anal pressure before operation was $16 \mathrm{mmHg}(1 \mathrm{mmHg}=0.133 \mathrm{kPa})$, and the corresponding postoperative resting pressure was $68 \mathrm{mmHg}$ (Wong et al., 1996). In three papers, Lehur et al. (1998; 2000; 2002) reported both preoperative and postoperative pressures and in one paper of Lehur et al. (1996) only postoperative values were given. Preoperative and postactivated pressures were also reported by Wong et al. (1996; 2002). The detailed data are shown in Table 2. The difference between preoperative and postoperative anorectal pressures was statistically significant $(P<0.0001)$. The increase in pressure indicates an improvement in function, but a strong correlation between pressure and continence has not been confirmed.

\subsubsection{Success rate of the device}

Twenty-two papers, in addition to another two papers (Romano et al., 2003; Meurette et al., 2009), reported the success rate of the device, i.e. the proportion of functional devices, which varied between 6\% (O'Brien et al., 2004) and 75\% (Altomare et al., 2001). In the papers of Lehur et al. (1996; 1998; $2000 ; 2002$ ), the proportions were $77 \%, 85 \%, 83 \%$, and $75 \%$, respectively, and in the paper of Wong et al. (2002), the proportion was $67 \%$. The success rate of the device was not low; however, the function of some devices decreased gradually with time.

The clinical applications presented in the aforementioned papers show that patients suffered from a variety of postoperative complications, including infection, erosion, mechanical failure, tissue ischemia, and evacuation difficulty. These resulted in a lot of re-operations, even a large proportion of explants. With regard to efficacy, there was a large difference between preoperative and postoperative FISs but this does not necessarily indicate that the effectiveness of the device was maintained. In addition, there was a significant improvement between preoperative and postoperative quality of life scores in patients with functional devices, but in explanted patients this was not reported. The increase in pressure indicates an improvement in function, but correlation between pressure and continence is still unclear. The success rate of the device was high but its function decreased gradually with time. Generally, the device does not maintain long-term efficacy. Some new AAS devices have now been developed.

\section{New studies on artificial anal sphincters}

\subsection{German Artificial Sphincter System}

H. Schrag, from the University of Freiburg, has developed the German Artificial Sphincter System. The prosthesis employs elastic compression cuffs inside a rigid carrier ring and reservoir cuffs at its outer side. A bidirectional silicon micropump transports body compatible liquid between both cuff systems (Fig. 2a). The new concept benefits from high integration of all functional components into one device. Thus, an easy surgical implantation technique and low risk of infection can be achieved (Schrag et al., 2004; Doll et al., 2006; 2007). To fulfill the rigid criteria for therapy transfer and minimally invasive implantation, the various functional components of the system were redesigned. The redesign comprises the aggregation of all electric and mechanical components into one central unit (Fig. 2b) (Ruthmann et al., 2010).

Table 2 Preoperative and postoperative anorectal pressures

\begin{tabular}{|c|c|c|}
\hline Author & Preoperative mean pressure & Postoperative mean pressure \\
\hline Lehur et al. (1998) & $\begin{array}{l}41(\mathrm{SD}, 10) \mathrm{cmH}_{2} \mathrm{O} \\
(=30(\mathrm{SD}, 7) \mathrm{mmHg})\end{array}$ & $\begin{array}{l}48(\mathrm{SD}, 10) \mathrm{cmH}_{2} \mathrm{O}(=35(\mathrm{SD}, 7) \mathrm{mmHg}, \text { cuff opened }) \\
72(\mathrm{SD}, 7) \mathrm{cmH}_{2} \mathrm{O}(=53(\mathrm{SD}, 5) \mathrm{mmHg} \text {, cuff closed })\end{array}$ \\
\hline Lehur et al. (2000) & 28 (range, 5-76) $\mathrm{mmHg}$ & $\begin{array}{l}30 \text { (range, 9-65) mmHg (cuff opened) } \\
60 \text { (range, 38-96) mmHg (cuff closed) }\end{array}$ \\
\hline Lehur et al. (2002) & $\begin{array}{l}42(\mathrm{SD}, 24) \mathrm{cmH}_{2} \mathrm{O} \\
(=31(\mathrm{SD}, 18) \mathrm{mmHg})\end{array}$ & $\begin{array}{l}35(\mathrm{SD}, 27) \mathrm{cmH}_{2} \mathrm{O}(=26(\mathrm{SD}, 20) \mathrm{mmHg}, \text { cuff opened }) \\
98(\mathrm{SD}, 23) \mathrm{cmH}_{2} \mathrm{O}(=72(\mathrm{SD}, 17) \mathrm{mmHg} \text {, cuff closed })\end{array}$ \\
\hline Wong et al. (2002) & 26 (range, $0-70$ ) $\mathrm{mmHg}$ & 46 (range, $14-77) \mathrm{mmHg}$ (at the 12 th month post-activation) \\
\hline
\end{tabular}

$1 \mathrm{cmH}_{2} \mathrm{O}=0.098 \mathrm{kPa} ; 1 \mathrm{mmHg}=0.133 \mathrm{kPa}$ 

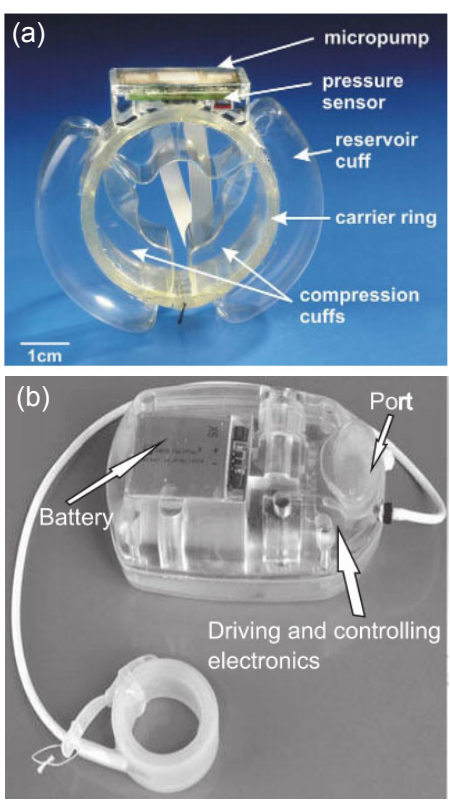

Fig. 2 German artificial sphincter system (a) and Modified prosthesis design (b)

(a) Reprinted from ref. (Doll et al., 2006), Copyright 2005, with permission from Elsevier; (b) Reproduced from ref. (Ruthmann et al., 2010) by permission of John Wiley and Sons

\subsection{Prosthetic anal sphincter}

To minimize local compression on the rectal wall, a "pillow-type" device has been developed by C.A. Hajivassiliou (Department of Paediatric Surgery, Royal Hospital for Sick Children, UK). This reproduces the action of the puborectalis by flattening and angulating the bowel muscle (Fig. 3). The design aims to reduce the stress concentration effect and overcome the risk of ischaemic complications by simulating the normal physiology of the anorectum, but the mechanical interaction between the artificial sphincter and the tissues was not discussed (Finlay et al., 2004).

\subsection{AAS system with sensor feedback}

The research team from the School of Electrical Engineering (SEE), Shanghai Jiao Tong University (SJTU), China, has presented a highly integrated and easily implantable sphincter prosthesis with sensor feedback based on transcutaneous energy transmission. It comprises mainly a reservoir, a front cuff, a sensor cuff, and a micropump with motor gear (Fig. 4) (Zan et al., 2008). Another developed AAS system is a novel machine-electrical-hydraulic muscle system that consists of an external telemetry unit, an internal
AAS, and a transcutaneous energy transfer system. Its efficiency in achieving continence was confirmed in vitro and in vivo in a pig model (Ke et al., 2014a; 2014b). A colonic blood flow model was presented and the electromagnetic effects on the biological tissue surrounding the transcutaneous transformer were studied (Zan et al., 2008; 2010).

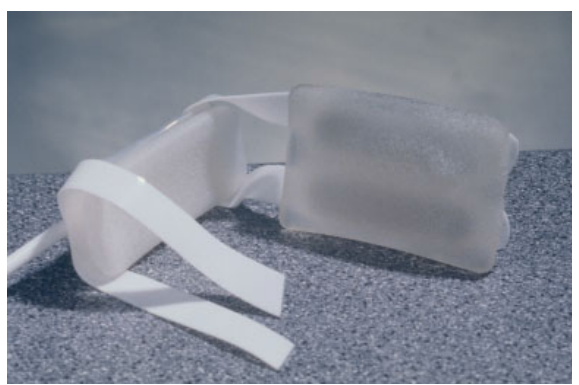

Fig. 3 Pillow-type prosthetic anal sphincter Reproduced from ref. (Finlay et al., 2004) by permission of John Wiley and Sons

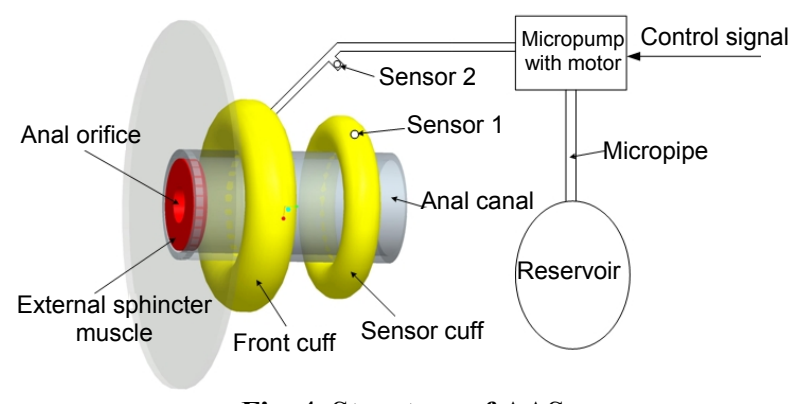

Fig. 4 Structure of AAS

Reprinted from ref. (Zan et al., 2008) with permission from Zhejiang University and Springer-Verlag GmBH

\subsection{Tohoku University artificial sphincter system}

Yun Luo (presently employed by SJTU) of Tohoku University proposed a novel AAS with a simple structure, using shape memory alloy (SMA). The basic design of the device is to use two elements implanted inside the body: an SMA based artificial sphincter and a secondary coil (Fig. 5) (Luo et al., 2006). Although the dimensions of the artificial sphincter are comparable to those of the silicone cuff in the AMS800, the secondary coil is disk-like and drastically reduces the volume of the implant. This enables the new device to be promoted as a low invasive prosthesis. In addition, it is expected to have enhanced reliability and durability due to the simplicity of the mechanism driving the device (Luo et al., 2004; 2006; Liu et al., 2007). 


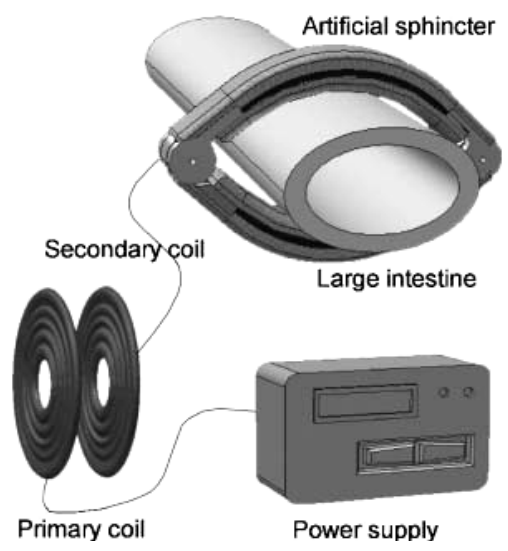

Fig. 5 Novel artificial sphincter using shape memory alloys and transcutaneous energy transmission technologies Reprinted from ref. (Luo et al., 2006) by permission of Taylor \& Francis (http://www.tandfonline.com)

\section{Discussion}

To find the reason for the limited application of AAS and establish its rightful position in treating FI, the safety and efficacy of AAS were assessed based on 24 papers about their clinical application.

Some serious shortcomings were identified in the statistical analysis reported in these papers. First of all, assessments were based on a small number of case studies, and could not provide sufficient evidence. The number of postoperative complications was unclear, patients were not randomly selected, and the lack of control groups reduced the reliability of the results. Most papers gave only the average values of the study group, not the data for each patient. Secondly, the number of patients studied was too small. The sample number in several studies was only six, seven, or eight patients. In addition, the follow-up period was too short, with a minimum of only 6 months. There were no follow-up results on failure of operation or device explantation. Whether unsuccessful surgeries may have physical or physiological effects on the patients was unclear. There was a lack of long term data on safety and efficacy. Finally, there was no uniform standard to define whether the technology was a success or failure. For example, the effect on continence was evaluated using four different scoring systems (WS, AMSFIS, CCS, and WCGS), and the QL using four different scoring systems (AMSQLS, RFIQLS, SF-36, and BDI).
Although the data have many shortcomings, general conclusions about the efficacy and safety of artificial sphincters can still be drawn.

As far as efficacy is concerned, all studies showed that the average FIS of patients with effective devices was significantly decreased after device implantation. However, there was no strong relationship between the average score and the number of patients with an effective device. The QL of patients with effective devices improved considerably after device implantation, but the QL of patients with failed surgery and device explantation was not reported. The difference in the anal resting pressure between the preoperative and postoperative stages was statistically considerable, but no correlation between pressures and continence could be confirmed. This kind of device is effective for patients who retain the device without major complications. However, the function gradually degenerates with time. Therefore, there is not enough evidence to prove that the device is effective in the long term.

As far as safety is concerned, the device also has many problems. The operation causes a wide range of complications, such as infection, erosion, tissue ischemia, mechanical failure, and evacuation difficulties. In all studies, infection was obvious and spread to some components or the entire device. The location of infection was mainly around the anus, and the high infection rate was due mainly to the use of prosthetic material in the anoperineal area. Erosion was located mainly in the anal, rectal, cuff, pump, pipe, or other component parts. There were many causes of erosion, such as organizational pressure, infections, inappropriate cuff size, the choice of balloon, tissue damage, a change in the position of elements, and repeated defecation straining. Among these reasons, organizational pressure was the most important. Tissue ischemia was another common complication, and its main cause was that the pressure of the artificial sphincter was too high. Mechanical complications were also common, including rupture of the cuff, loss of system fluid, disconnection of any component, and malfunction or migration of the control pump. The main causes were the complexity of the device and the connectivity of its components. Another complication was the incidence of evacuation difficulties. These may be caused by the circumference of the cuff being too small or the time during which the sphincter is open being too short. Other complications were 
pain, rectal prolapse, fever, and hematoma. Many complications result in surgical revision. The incidence of complications shows that the artificial sphincter can have side-effects on patients.

A perfect anal sphincter should be effective and reliable, easy to operate, and cause no harm to patients. Therefore, the current artificial sphincter cannot be widely used as a safe and effective device in clinical application. The main reason is the high infection rate, which goes hand in hand with the significant rate of explantation. Some new devices have been developed to achieve long-term safety and efficacy. The newly developed German Artificial Sphincter System is a highly integrated and efficient prosthesis with a very low risk of intestinal ischemic injury (Doll et al., 2006). C.A. Hajivassiliou developed a prosthetic anal sphincter, which aims to reduce stress concentration (Finlay et al., 2004). However, the mechanical interaction between the artificial sphincter and the tissues was not reported. The research team from SEE, SJTU highly integrated all the components with sensor feedback to make surgical implantation easy and at low risk (Zan et al., 2008). Yun Luo developed an AAS device with a reduced number of parts and a compact structure for a less invasive prosthesis (Luo et al., 2006). In preliminary studies, Yun Luo found that the thickness of tissue around the implant was changed dramatically by a stress shielding effect caused by the large mechanical stimulus. The stress shielding effect makes the force between the implant and its surrounding tissues unbalanced, causing the device to be ineffective and leading to ischemic necrosis and tissue atrophy. Therefore, the most critical issue of AAS is to maintain long-term biomechanical compatibility between the artificial sphincter and the surrounding tissue in clinical applications.

This paper presents a novel concept involving embedding smart materials in a device to improve biomechanical compatibility. Our research group is studying the use of the mechanical properties of smart materials to develop a device that remains functional under changing mechanical properties caused by the stress shielding effect and that will not damage the intestinal tissue.

\section{Conclusions}

Our assessment of studies on the safety and efficacy of the AMS series sphincter shows that the results are unsatisfactory. In terms of safety, the devices cause a high rate of explantation and surgical revision. The high frequency of infection, erosion, and tissue ischemia could harm patients. In terms of efficacy, there is insufficient evidence to prove that the devices can maintain a long-term functional status. Against this background, some new devices have been developed to solve the safety and efficacy issues. However, so far, no device can successfully realize the clinical application. Implantation of an artificial sphincter may lead to morphological change in the surrounding tissues. Related biomechanical imbalance could result in the loss of effectiveness of the device and various complications. Therefore, we conclude that maintaining long-term biomechanical compatibility between implants and their surrounding tissues is the key issue for achieving permanent continence in the human body. The proposed method using smart materials in the device may improve biomechanical compatibility.

\section{Compliance with ethics guidelines}

Ming-hui WANG, Ying ZHOU, Shuang ZHAO, and Yun LUO declare that they have no conflict of interest.

This article does not contain any studies with human or animal subjects performed by any of the authors.

\section{References}

Altomare, D., Dodi, G., La Torre, F., et al., 2001. Multicentre retrospective analysis of the outcome of artificial anal sphincter implantation for severe faecal incontinence. $\mathrm{Br}$. J. Surg., 88(11):1481-1486. [doi:10.1046/j.0007-1323. 2001.01895.x]

Altomare, D., Binda, G., Dodi, G., et al., 2004. Disappointing long-term results of the artificial anal sphincter for faecal incontinence. Br. J. Surg., 91(10):1352-1353. [doi:10. 1002/bjs.4600]

AMS (American Medical Systems), 1999. Important information for patients considering an Acticon ${ }^{\mathrm{TM}}$ Neosphincter. Available from http://www.fda.gov/ohrms/dockets/ac/01/ briefing/3777b1_02_patient\%20info.pdf [Accessed on Mar. 23, 2014].

Baig, M., Wexner, S., 2000. Factors predictive of outcome after surgery for faecal incontinence. Br. J. Surg., 87(10): 1316-1330. [doi:10.1046/j.1365-2168.2000.01592.x]

Casal, E., San Ildefonso, A., Carracedo, R., et al., 2004. Artificial bowel sphincter in severe anal incontinence. Colorectal Dis., 6(3):180-184. [doi:10.1111/j.1463-1318. 2004.00609.x]

Chittawatanarat, K., Koh, D.C., Seah, A.A., et al., 2010. Artificial bowel sphincter implantation for faecal incontinence in Asian patients. Asian J. Surg., 33(3):134-142. [doi:10.1016/S1015-9584(10)60023-1] 
Christiansen, J., 2000. The artificial anal sphincter. Can. J. Gastroenterol., 14:152D-154D.

Christiansen, J., Lorentzen, M., 1987. Implantation of artificial sphincter for anal incontinence. Lancet, 330(8553): 244-245. [doi:10.1016/S0140-6736(87)90829-4]

Christiansen, J., Rasmussen, O., Lindorff-Larsen, K., 1999. Long-term results of artificial anal sphincter implantation for severe anal incontinence. Ann. Surg., 230(1):45-48. [doi:10.1097/00000658-199907000-00007]

Devesa, J.M., Rey, A., Hervas, P.L., et al., 2002. Artificial anal sphincter. Dis. Colon Rectum, 45(9):1154-1163. [doi:10. 1007/s10350-004-6382-y]

Dodi, G., Melega, E., Masin, A., et al., 2000. Artificial bowel sphincter (ABS) for severe faecal incontinence: a clinical and manometric study. Colorectal Dis., 2(4):207-211. [doi:10.1046/j.1463-1318.2000.00157.x]

Doll, A., Heinrichs, M., Goldschmidtboeing, F., et al., 2006. A high performance bidirectional micropump for a novel artificial sphincter system. Sensor. Actuat. A-Phys., 130-131: 445-453. [doi:10.1016/j.sna.2005.10.018]

Doll, A.F., Wischke, M., Geipel, A., et al., 2007. A novel artificial sphincter prosthesis driven by a four-membrane silicon micropump. Sensor. Actuat. A-Phys., 139(1-2): 203-209. [doi:10.1016/j.sna.2007.03.025]

Finlay, I., Richardson, W., Hajivassiliou, C.A., 2004. Outcome after implantation of a novel prosthetic anal sphincter in humans. Br. J. Surg., 91(11):1485-1492. [doi:10.1002/ bjs.4721]

Gallas, S., Leroi, A.M., Bridoux, V., et al., 2009. Constipation in 44 patients implanted with an artificial bowel sphincter. Int. J. Colorectal Dis., 24(8):969-974. [doi:10.1007/ s00384-009-0693-3]

Gregorcyk, S.G., 2005. The current status of the Acticon ${ }^{\circledR}$ Neosphincter. Clin. Colon Rectal Surg., 18(1):32-37. [doi:10.1055/s-2005-864078]

Jorge, J.M.N., Wexner, S.D., 1993. Etiology and management of fecal incontinence. Dis. Colon Rectum, 36(1):77-97. [doi:10.1007/BF02050307]

Kaiser, A.M., Orangio, G.R., Zutshi, M., et al., 2014. Current status: new technologies for the treatment of patients with fecal incontinence. Surg. Endosc., 28(8):2277-2301. [doi: 10.1007/s00464-014-3464-3]

Ke, L., Yan, G.Z., Yan, S., et al., 2014a. Coupling analysis of transcutaneous energy transfer coils with planar sandwich structure for a novel artificial anal sphincter. J. Zhejiang Univ.-Sci. C (Comput. \& Electron.), 15(11):1021-1034. [doi:10.1631/jzus.C1400062]

Ke, L., Yan, G.Z., Liu, H., et al., 2014b. A novel artificial anal sphincter system in an in vitro and in vivo experiment. Int. J. Artif. Organs, 37(3):253-263. [doi:10.5301/ijao.5000312]

Lehur, P.A., Michot, P.F., Denis, P., et al., 1996. Results of artificial sphincter in severe anal incontinence. Dis. Colon Rectum, 39(12):1352-1355. [doi:10.1007/BF02054523]

Lehur, P.A., Glemain, P., des Varannes, S.B., et al., 1998. Outcome of patients with an implanted artificial anal sphincter for severe faecal incontinence. A single institu- tion report. Int. J. Colorectal Dis., 13(2):88-92. [doi:10. 1007/s003840050141]

Lehur, P.A., Roig, J.V., Duinslaeger, M., 2000. Artificial anal sphincter. Dis. Colon Rectum, 43(8):1100-1106. [doi:10. 1007/BF02236557]

Lehur, P.A., Zerbib, F., Neunlist, M., et al., 2002. Comparison of quality of life and anorectal function after artificial sphincter implantation. Dis. Colon Rectum, 45(4):508-513. [doi:10.1007/s10350-004-6230-0]

Liu, H., Luo, Y., Higa, M., et al., 2007. Biochemical evaluation of an artificial anal sphincter made from shape memory alloys. J. Artif. Organs, 10(4):223-227. [doi:10. 1007/s10047-007-0395-y]

Luo, Y., Takagi, T., Okuyama, T., et al., 2004. Functional evaluation of an artificial anal sphincter using shape memory alloys. ASAIO J., 50(4):338-343.

Luo, Y., Higa, M., Amae, S., et al., 2006. Preclinical development of SMA artificial anal sphincters. Minim. Invasive Ther. Allied Technol., 15(4):241-245. [doi:10.1080/ 13645700600836695]

Lustman, P.J., Clouse, R.E., Griffith, L.S., et al., 1997. Screening for depression in diabetes using the beck depression inventory. Psychosom. Med., 59(1):24-31. [doi:10. 1097/00006842-199701000-00004]

Madoff, R.D., Parker, S.C., Varma, M.G., 2004. Faecal incontinence in adults. Lancet, 364(9434):621-632. [doi:10. 1016/S0140-6736(04)16856-6]

Malouf, A.J., Vaizey, C.J., Kamm, M.A., 2000. Reassessing artificial bowel sphincters. Lancet, 355(9222):2219-2220. [doi:10.1016/S0140-6736(00)02409-0]

Meurette, G., la Torre, M., Regenet, N., et al., 2009. Value of sacral nerve stimulation in the treatment of severe faecal incontinence: a comparison to the artificial bowel sphincter. Colorectal Dis., 11(6):631-635. [doi:10.1111/j.14631318.2008.01633.x]

Michot, F., Costaglioli, B., Leroi, A.M., 2003. Artificial anal sphincter in severe fecal incontinence: outcome of prospective experience with 37 patients in one institution. Ann. Surg., 237(1):52-56. [doi:10.1097/00000658-2003 01000-00008]

Mitchell, P.J., Sagar, P.M., 2014. Emerging surgical therapies for faecal incontinence. Nat. Rev. Gastroenterol. Hepatol., 11(5):279-286. [doi:10.1038/nrgastro.2013.220]

Mundy, L., Merlin, T.L., Maddern, G.J., 2004. Systematic review of safety and effectiveness of an artificial bowel sphincter for faecal incontinence. Br. J. Surg., 91(6): 665-672. [doi:10.1002/bjs.4587]

Nandivada, P., Nagle, D., 2014. Surgical therapies for fecal incontinence. Curr. Opin. Gastroenterol., 30(1):69-74. [doi:10.1097/MOG.0000000000000029]

O'Brien, P.E., Skinner, S., 2000. Restoring control. Dis. Colon Rectum, 43(9):1213-1216. [doi:10.1007/BF02237423]

O'Brien, P.E., Dixon, J.B., Skinner, S., et al., 2004. A prospective, randomized, controlled clinical trial of placement of the artificial bowel sphincter (Acticon Neosphincter) for the control of fecal incontinence. Dis. 
Colon Rectum, 47(11):1852-1860. [doi:10.1007/s10350004-0717-6]

Ortiz, H., Armendariz, P., Demiguel, M., et al., 2002. Complications and functional outcome following artificial anal sphincter implantation. Br. J. Surg., 89(7):877-881. [doi:10.1046/j.1365-2168.2002.02137.x]

Parker, S.C., Spencer, M.P., Madoff, R.D., et al., 2003. Artificial bowel sphincter. Dis. Colon Rectum, 46(6):722-729. [doi:10.1007/s10350-004-6647-5]

Perry, S., Shaw, C., Mcgrother, C., et al., 2002. Prevalence of faecal incontinence in adults aged 40 years or more living in the community. Gut, 50(4):480-484. [doi:10.1136/gut. 50.4.480]

Rao, S.S., 2004. Diagnosis and management of fecal incontinence. Am. J. Gastroenterol., 99(8):1585-1604. [doi:10. $1111 / \mathrm{j} .1572-0241.2004 .40105 . \mathrm{x}]$

Rojas, R.G., Atan, I.K., Shek, K.L., et al., 2014. Anal sphincter trauma and fecal incontinence in urogynecological patients. Neurourol. Urodynam., 33(6):856-858.

Romano, G., la Torre, F., Cutini, G., et al., 2003. Total anorectal reconstruction with the artificial bowel sphincter: report of eight cases. Dis. Colon Rectum, 46(6):730-734. [doi:10.1007/s10350-004-6649-3]

Ruiz Carmona, M.D., Alós Company, R., Roig Vila, J.V., et al., 2009. Long-term results of artificial bowel sphincter for the treatment of severe faecal incontinence. Are they what we hoped for? Colorectal Dis., 11(8):831-837. [doi:10. 1111/j.1463-1318.2008.01652.x]

Ruthmann, O., Richter, S., Seifert, G., et al., 2010. The first teleautomatic low-voltage prosthesis with multiple therapeutic applications: a new version of the German Artificial Sphincter System. Artif. Organs, 34(8):635-641. [doi:10.1111/j.1525-1594.2010.01004.x]

Savoye, G., Leroi, A., Denis, P., 2000. Manometric assessment of an artificial bowel sphincter. Br. J. Surg., 87(5): 586-589. [doi:10.1046/j.1365-2168.2000.01398.x]

Schrag, H., Padilla, F., Doll, A., et al., 2004. German Artificial Sphincter System-GASS. Development and in vitro evaluation of a novel, fully-implantable, highly integrated sphincter prosthesis for therapy of high-grade fecal incontinence. Biomed. Tech., 49(10):274-278 (in German).

Tan, J.J., Chan, M., Tjandra, J.J., 2007. Evolving therapy for fecal incontinence. Dis. Colon Rectum, 50(11):1950-1967. [doi:10.1007/s10350-007-9009-2]

Teunissen, T., van den Bosch, W., van den Hoogen, H., et al., 2006. Prevalence of urinary and faecal incontinence among community-dwelling elderly patients in Nijmegen, the Netherlands, January 1999-July 2001. Ned. Tijdschr. Geneeskd., 150(44):2430-2434 (in Dutch).
Tobin, G.W., Brocklehurst, J., 1986. Faecal incontinence in residential homes for the elderly: prevalence, aetiology and management. Age Ageing, 15(1):41-46. [doi:10.1093/ ageing/15.1.41]

Vaizey, C.J., Kamm, M.A., Gold, D.M., et al., 1998. Cinical, physiological, and radiological study of a new purposedesigned artifical bowel sphincter. Lancet, 352(9122): 105-109. [doi:10.1016/S0140-6736(98)85014-9]

Vaizey, C.J., Carapeti, E., Cahill, J.A., et al., 1999. Prospective comparison of faecal incontinence grading systems. Gut, 44(1):77-80. [doi:10.1136/gut.44.1.77]

Walter, S., Hallböök, O., Gotthard, R., et al., 2002. A populationbased study on bowel habits in a Swedish community: prevalence of faecal incontinence and constipation. Scand. J. Gastroenterol., 37(8):911-916. [doi:10.1080/ 003655202760230865]

Wong, W.D., Jensen, L.L., Bartolo, D.C., et al., 1996. Artificial anal sphincter. Dis. Colon Rectum, 39(12):1345-1351. [doi:10.1007/BF02054522]

Wong, W.D., Congliosi, S.M., Spencer, M.P., et al., 2002. The safety and efficacy of the artificial bowel sphincter for fecal incontinence. Dis. Colon Rectum, 45(9):1139-1153. [doi:10.1007/s10350-004-6381-z]

Zan, P., Yan, G.Z., Liu, H., 2008. Modeling of human colonic blood flow for a novel artificial anal sphincter system. $J$. Zhejiang Univ.-Sci. B, 9(9):734-738. [doi:10.1631/jzus. B0820099]

Zan, P., Yang, B.H., Shao, Y., et al., 2010. Electromagnetic effects on the biological tissue surrounding a transcutaneous transformer for an artificial anal sphincter system. J. Zhejiang Univ.-Sci. B (Biomed. \& Biotechnol.), 11(12): 931-936. [doi:10.1631/jzus.B1000058]

\section{中文概要}

\section{题 目: 人工肛门括约肌临床应用所面临的挑战 \\ 概 要: 本文对目前临床使用的人工括约肌的安全性与有 效性进行分析与讨论, 对国内外目前正在开发的 新装置和新方法进行比较, 归纳出人工肛门括约 肌在临床应用中遇到的关键问题是维持植入体 与周围生物组织的远期力学相容性, 该问题有望 通过智能材料的利用得到解决。}

关键词: 大便失禁; 人工肛门括约肌；生物力学相容性; 智能材料 